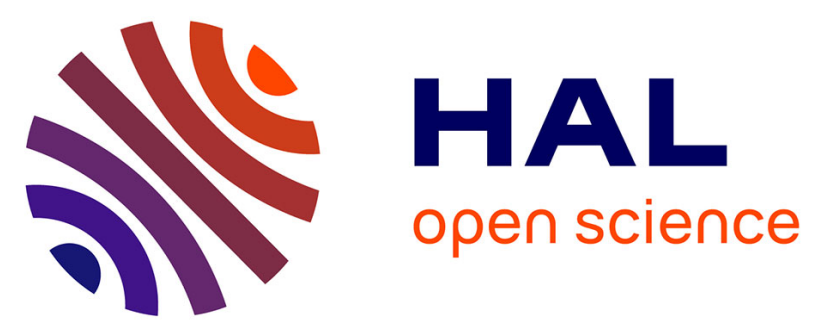

\title{
An Efficient Control of a Series Connected Two-Synchronous Motor 5-Phase with Non Sinusoidal EMF Supplied by a Single 5-leg VSI: Experimental and Theoretical Investigations
}

Fatiha Mekri, Jean Fréderic Charpentier, Eric Semail

\section{To cite this version:}

Fatiha Mekri, Jean Fréderic Charpentier, Eric Semail. An Efficient Control of a Series Connected Two-Synchronous Motor 5-Phase with Non Sinusoidal EMF Supplied by a Single 5-leg VSI: Experimental and Theoretical Investigations. Electric Power Systems Research, 2012, 92, pp.11-19. 10.1016/j.epsr.2012.05.012 . hal-00794363

\section{HAL Id: hal-00794363 \\ https://hal.science/hal-00794363}

Submitted on 25 Feb 2013

HAL is a multi-disciplinary open access archive for the deposit and dissemination of scientific research documents, whether they are published or not. The documents may come from teaching and research institutions in France or abroad, or from public or private research centers.
L'archive ouverte pluridisciplinaire HAL, est destinée au dépôt et à la diffusion de documents scientifiques de niveau recherche, publiés ou non, émanant des établissements d'enseignement et de recherche français ou étrangers, des laboratoires publics ou privés. 


\title{
An Efficient Control of a Series Connected Two-Synchronous Motor 5-Phase with Non Sinusoidal EMF Supplied by a Single 5-leg VSI: Experimental and Theoretical Investigations
}

\author{
MEKRI Fatiha *, a \\ CHARPENTIER Jean fréderic * \\ SEMAIL Eric $* *$ \\ * IRENav : Institut de Recherche de l'Ecole Navale EA3634 - BP 600, 29240 BREST ARMEES, France \\ ** : L2EP: Laboratoire d'Electrotechnique et d'Electronique de Puissance de LILLE, 8 Bd Louis XIV, \\ 59046 Lille, France
}

${ }^{\mathrm{a}}$ Corresponding author. fmekri@gmail.com

\begin{abstract}
This paper proposes the control scheme of an original drive which is made up of two 5-phase Permanent Magnet Synchronous Machines (PMSM) connected in series. Even if the Electro-Motive Force (EMF) are trapezoidal, it is possible, by using a special series connection between the two machines and by implementing a special vector control, to impose independent torques and speeds with a single five-leg Voltage Source Inverter (VSI). This configuration allows an independent control of two PM machines and needs only five legs instead of six-legs for a classical solution using two independent three phase inverters supplying two three-phase machines. If special series-connection with classical vector control is sufficient to achieve flux/torque decoupling when the EMFs are sinusoidal, it is necessary to modify the control scheme when the EMFs are not sinusoidal.

Simulations and experimental results demonstrate efficiency of the independent control of the two 5phase synchronous machines connected in series, and the efficiency of the improved control for different loads.
\end{abstract}

Keywords: Multi-machine drives, series connection, modelling, vector control, five-phase machine; five- 
leg Voltage Source Inverter

\section{Introduction}

Multi-phase drives benefit from a higher fault tolerance than classical wye-coupled three-phase drives. In aerospace motors $[1,2,3,4]$ and marine applications $[5,6,7]$, multiphase drives are widely used. In electrical ships the use of two propellers is often needed [8]. When one power converter fails, it is then remaining one propeller for controlling the ship propulsion. Nevertheless, the manoeuvrability and the hydrodynamic efficiency are dropping when using only one propeller. In this case, it should be of better interest to use the remaining healthy converter to control simultaneously the two propellers even if these two propellers are used at reduced power. This strategy is possible with the drive studied in this paper which is based on a particular series connection of two machines.

This kind of series-connection which is described in figure 1 has been widely studied in case of induction and synchronous machines $[9,10,11,12]$, modelled with a first harmonic approach concerning EMF and magnetomotive forces. In this case, simulation and experimental results have confirmed the possibility to control independently (n-1)/2 n-phase motors in series connection with only one n-leg VSI $[13,14]$. As far as the VSI is not saturated and machines have sinusoidal EMF, a simple vector control, extended from well-known 3-phase one, allows to guarantee that speed and torque in one machine have no impact on speed and torque in the other machine.

Nevertheless, an advantage of the multiphase machines is the possibility to use harmonics of EMF in order to increase the torque density. This is why the use of two motors with non-sinusoidal electromotive forces can be an attractive solution for particular applications as marine propulsion or aerospace drives where highly compact systems are needed [7]. Moreover in case of the use of PM machine, classical design leads to non-sinusoidal EMF machines rather than sinusoidal EMF machines. In this case of non sinusoidal EMF machine the problem is that a strong coupling is induced between non-sinusoidal EMF multiphase drives if the control developed in [9-11] is used. Torque pulsations in one motor are then depending on the speed of the other motor.

In [14], a simulation of two 5-phase synchronous motors with trapezoidal EMF shows that it is still possible, by using decoupling method, to control independently the two machines with a constant torque 
for each one. In [14], the implementation of the control is not detailed and a special methodology (Energetic Macroscopic Representation) is used in order to deduce the control structure. The presented paper is based on a more classical control approach and provides details for practical implementation: experimental results obtained in a low power bench confirms the possibility to take into account the harmonics of EMF in the control in order to ensure a low level of torque pulsations.

In the first section, the principles of the special connection are reminded with focusing on a PM multiphase machine modelling and the effect of the presence of a third harmonic in the EMF in a 25 phase machine series configuration.

In the second section, the control scheme of the currents is detailed. This control scheme is based on a mathematical modelling theory of multi-phase machine. This theory is based on the vectorial decomposition of the multiphase machine into a set of three machines (one 1-phase and two 2-phase machines), developed in $[15,16,17,18]$. These one-phase and two-phase subsystems, which are called

fictitious machines, are magnetically decoupled. Moreover, each of these subsystem machines is characterized by a particular harmonic family $[19,20,21]$. The detailed analysis of a series connection of two 5-phase machines supplied by a single 5-leg VSI is deduced logically from this theory and an efficient control strategy is presented $[21,22,23]$ : it is then easy to understand why it is possible to control independently two machines with sinusoidal EMF even if only one 5-leg VSI is used. Furthermore, the influence of high EMF harmonics on the vector control is examined. In the case of such a series connection, controlling a constant torque is not obvious because the flux / torque producing currents of one machine interact with the higher harmonics of the EMF of the second machine. These interactions can lead to undesirable torque ripples. However it is possible to compensate these harmonic torque ripples by improving the control structure.

Finally, simulations and experimental results are presented to demonstrate the decoupling of the control of the two machines and the efficiency of the proposed approach in terms of torque quality.

\section{Modelling two 5-phase machines with series connection}

\subsection{Multi-machine vectorial modelling of a 5-phase permanent magnet synchronous machine.}

The electric equations of a 5-phase permanent magnet synchronous machine in the natural stator 
frame are given by the following expression for each phase:

$$
v_{k}=R_{s} i_{k}+\frac{d \phi_{s k}}{d t}+e_{k}
$$

where $R_{S}$ is the resistance of the stator phase, $\Phi_{s k}$ is the flux component linked by the $\mathrm{k}^{\text {th }}$ phase and due to the stator currents, and finally $\boldsymbol{e}_{k}$ is the EMF induced in this phase by the permanent magnet rotor.

We consider that the five phases are regularly shifted, and that there is no saturation and no saliency effects. Then we can obtain a relation between current vector (5 components) and stator flux vector [21, $22,24]$.

$$
\vec{\phi}_{s}=\lambda(\vec{i})
$$

$$
\left[L_{s}^{n}\right]=\operatorname{mat}\left(\lambda, B^{n}\right)=\left[\begin{array}{ccccc}
L & M_{1} & M_{2} & M_{2} & M_{1} \\
M_{1} & L & M_{1} & M_{2} & M_{2} \\
M_{2} & M_{1} & L & M_{1} & M_{2} \\
M_{2} & M_{2} & M_{1} & L & M_{1} \\
M_{1} & M_{2} & M_{2} & M_{1} & L
\end{array}\right]
$$

Where $L$ is the self-inductance of one phase, $M_{l}$ the mutual inductance between two adjacent phases (electrical shift angle $\pm \frac{2 \pi}{5}$ and $M_{2}$ is the mutual inductance between two phases shifted of an electrical angle of $\left.\pm \frac{4 \pi}{5}\right)$

The magnetic coupling between phases makes the control of a 5-phase machine complex. To simplify the dynamic control of such a system, it is possible to work in a new frame in which the phases are magnetically decoupled. This new frame is obtained by applying a generalized Concordia transform $\left(\left[\mathrm{C}_{5}\right]\right.$ matrix) defined in [25] and reminded in appendix.

In this new frame, these voltage equations can be expressed in one axis and two $2 \mathrm{D}$ planes which are magnetically decoupled. This axis and these two planes are associated with three fictitious machines (one 1-phase subsystem and two 2-phase subsystems) which are called respectively zero-sequence subsystem, main subsystem machine (MM) and secondary subsystem machine (SM) $[18,20]$. The components of the three corresponding subsystems are respectively noted with indexes $\left[z,\left(\alpha_{m}, \beta_{m}\right),\left(\alpha_{s}, \beta_{s}\right)\right]$. The electrical behavior of these subsystems is summarized by equation system (3). This system results of the 
transformation of (1) in the new frame.

$$
\begin{aligned}
& \vec{v}_{z}=R_{s} \vec{i}_{z}+\Lambda_{z} \frac{d \vec{i}_{z}}{d t}+\vec{e}_{z} \\
& \vec{v}_{\alpha \beta-m}=R_{s} \vec{i}_{\alpha \beta-m}+\Lambda_{m} \frac{d \vec{i}_{\alpha \beta-m}}{d t}+\vec{e}_{\alpha \beta-m} \\
& \vec{v}_{\alpha \beta-s}=R_{s} \vec{i}_{\alpha \beta-s}+\Lambda_{s} \frac{d \vec{i}_{\alpha \beta-s}}{d t}+\vec{e}_{\alpha \beta-s}
\end{aligned}
$$

- $\vec{v}_{z}, \vec{i}_{z}, \vec{e}_{z}$ are the voltage, current and EMF vectors of zero-sequence subsystem and $\Lambda_{z}$ is its inductance. It can be noticed that the current in this zero-sequence subsystem is nullified if a wye connection is used.

- $\vec{v}_{\alpha \beta-m}, \vec{i}_{\alpha \beta-m}, \vec{e}_{\alpha \beta-m}$ are the voltage, current and EMF vectors of main subsystem and $\Lambda_{m}$ its inductance.

- $\vec{v}_{\alpha \beta-s}, \vec{i}_{\alpha \beta-s}, \vec{e}_{\alpha \beta-s}$ are the voltage, current and EMF vectors of secondary one and $\Lambda_{s}$ its inductance.

$\Lambda_{z}, \Lambda_{m}, \Lambda_{s}$ are the eigenvalues of matrix defined in (2).

Each of these subsystems is associated with a particular harmonic family $[7,13]$ :

$$
\begin{aligned}
& \overrightarrow{\boldsymbol{e}}_{z}=\sqrt{5} \sum_{k} E^{k} \sin (h p \theta) \vec{x}_{z}, \mathrm{k}=5,15, \ldots \\
& \vec{e}_{\alpha \beta-m}=\sqrt{\frac{5}{2} \sum_{\mathrm{k}} E^{k}\left(\sin (h p \theta) \vec{x}_{m \alpha}-\cos (h p \theta) \vec{x}_{m \beta}\right), \mathrm{k}=1,9, \ldots} \\
& \vec{e}_{\alpha \beta-s}=\sqrt{\frac{5}{2}} \sum_{k} E^{k}\left(\sin (h p \theta) \vec{x}_{s \alpha}+\cos (h p \theta) \vec{x}_{s \beta}\right), \mathrm{k}=3,7, \ldots
\end{aligned}
$$

In the previous equations, $E^{k}$ is the peak value of the $\mathrm{k}^{\text {th }}$ harmonic of the EMF (in a PM machine EMF waveform is often trapezoidal as shown in fig. 2 and table 1 which presents one phase EMF of one of the two tested experimental machines ). According to this harmonic repartition, we can then consider that the MM subsystem has p pairs of poles and the SM subsystem has 3p pairs of poles. As shown in (3), the system behaves as if there were two two-phase subsystems magnetically decoupled and mechanically coupled. So it is possible to control the MM and SM currents independently.

The electromagnetic torque developed by the machine is equal to: 


$$
\begin{aligned}
& T_{e m}=\frac{\vec{e} \cdot \vec{i}}{\Omega}=\frac{\vec{e}_{z} \vec{i}_{z}+\vec{e}_{m} \cdot \vec{i}_{m}+\vec{e}_{s} \cdot \vec{i}_{s}}{\Omega} \\
& T_{e m}=\frac{\vec{e}_{m} \cdot \vec{i}_{m}+\vec{e}_{s} \cdot \vec{i}_{s}}{\Omega}=T_{m}+T_{s}
\end{aligned}
$$

The total electromagnetic torque of a 5-phase machine can be seen as the sum the two phase subsystems torque contributions (MM and SM) if a wye connection is used (in this case the current in the zero-sequence machine is nullified).

In normal operation with one machine associated with a 5-leg VSI, a way to produce a significant torque is to control each of these two 2-phase fictitious machines by imposing a sinusoidal current which corresponds to the first harmonic of each subsystem harmonic family. That means that the current is a compound of the fundamental harmonic (main subsystem currents) and a third harmonic (secondary subsystem currents) $[7,14]$. Therefore, the control of a 5-phase PMSM can be simplified by the use of two rotation transformations associated with each 2-phase subsystem (main and secondary). This transformation leads to define two d-q rotating frames [17]. The first frame is associated with the first harmonics and rotates at $\omega$, and the second one is associated with the third harmonic and rotates at $-3 \omega$. This transformation is a generalization, for multiphase system [14, 25], of the Park theory and allows a better control of the system using classical controllers (PI, PID) because the reference currents are constant in steady state in these two d-q frames.

\subsection{Multi-machine vectorial modeling of two 5-phase series-connected machines.}

In the studied configuration, the system consists in two 5-phase PMSM supplied by a single 5-leg VSI. Fig.1 illustrates the series connection of the stator windings of the two real machines, with an appropriate phase transposition, which is detailed in $[11,13]$. This particular connection leads to the possibility of an independent control of the two machines.

Based on this special connection between the two machines (fig.1) the voltages of the inverter are related to individual machine phase voltage, and can be expressed by:

$\left\{\begin{array}{l}v_{A}=v_{a 1}+v_{a 2} \\ v_{B}=v_{b 1}+v_{c 2} \\ v_{C}=v_{c 1}+v_{e 2} \\ v_{D}=v_{d 1}+v_{b 2} \\ v_{E}=v_{e 1}+v_{d 2}\end{array}\right.$ 
The inverter output currents are given by:

$$
\left\{\begin{array}{l}
i_{A}=i_{a 1}=i_{a 2} \\
i_{B}=i_{b 1}=i_{c 2} \\
i_{C}=i_{c 1}=i_{e 2} \\
i_{D}=i_{d 1}=i_{b 2} \\
i_{E}=i_{e 1}=i_{d 2}
\end{array}\right.
$$

If the generalized Concordia transform ([C5] matrix) described in previous paragraph is applied to the system represented by fig. 1, a new system in the new reference frame is given by (8). Therefore, the series connection between machines 1 and 2 can be interpreted as follow: subsystem MM2 and SM1 are connected in series, and subsystem SM2 and MM1 are also connected in series [13].

$\left\{\begin{array}{l}\vec{i}_{m}=\vec{i}_{m 1}=\vec{i}_{s 2}{ }^{*} \\ \vec{i}_{s}=\vec{i}_{s 1}=\vec{i}_{m 2}\end{array}\right.$

With $\left\{\begin{array}{l}\vec{i}_{m 1}=\left[\begin{array}{ll}i_{m \alpha 1} & i_{m \beta 1}\end{array}\right]^{t}=\left[\begin{array}{ll}i_{s \alpha 2} & -i_{s \beta 2}\end{array}\right]^{t} \\ \vec{i}_{s 1}=\left[\begin{array}{ll}i_{s \alpha 1} & i_{s \beta 1}\end{array}\right]^{t}=\left[\begin{array}{ll}i_{m \alpha 2} & i_{m \beta 2}\end{array}\right]^{t}\end{array}\right.$

With:

$-\left(\vec{i}_{m}, \vec{i}_{s}\right),\left(\vec{i}_{m 1}, \vec{i}_{s 1}\right),\left(\vec{i}_{m 2}, \vec{i}_{s 2}\right)$ are main and secondary subsystems currents for inverter, first machine and second machine.

- $\quad \bar{i}_{s 2}{ }^{*}$ is the conjugate of $\vec{i}_{s 2}$ (Appendix)

The windings are wye-connected. So the zero-sequence component of the currents is null. Then we can write:

$$
\begin{gathered}
\vec{v}_{m}=\left(R_{m 1}+R_{s 2}\right) \vec{i}_{m 1}+\left(\Lambda_{m 1}+\Lambda_{s 2}\right) \frac{d \vec{i}_{m 1}}{d t}+\vec{e}_{m 1}+\vec{e}_{s 2}^{*} \\
\vec{v}_{s}=\left(R_{s 1}+R_{m 2}\right) \vec{i}_{s 1}+\left(\Lambda_{m 2}+\Lambda_{s 1}\right) \frac{d \vec{i}_{s 1}}{d t}+\vec{e}_{s 1}+\vec{e}_{m 2}
\end{gathered}
$$

- For the first 2-phase subsystem components of VSI voltages (which correspond to MM1 and SM2 subsystems current), the series connection of the two machines implies that:

$$
\begin{aligned}
& \text { - } R_{m 1} \text { is added to } R_{s 2} \text { to give a global resistance: } R_{m}=R_{s 2}+R_{m 1} \\
& \text { - } \Lambda_{s 2} \text { is added to } \Lambda_{m 1} \text { to give a global inductance: } \Lambda_{m}=\Lambda_{s 2}+\Lambda_{m 1} .
\end{aligned}
$$


- $\vec{e}_{m 1}$ is added to $\vec{e}_{s 2}^{*}$ to give a global EMF: $\quad \vec{e}_{m}: \vec{e}_{m}=\vec{e}_{m 1}+\vec{e}_{s 2}^{*}$

- For the second 2-phase subsystem components of VSI voltage (which correspond to SM1 and MM2 subsystems current), the series connection of the two machines implies that:

- $R_{s l}$ is added to $R_{m 2}$ to give a global resistance: $\quad R_{s}=R_{m 2}+R_{s 1}$

- $\Lambda_{m 2}$ is added to $\Lambda_{s 1}$ to give a global inductance: $\Lambda_{s}=\Lambda_{m 2}+\Lambda_{s 1}$.

- $\vec{e}_{s 1}$ is added to $\vec{e}_{m 2}$ to give a global EMF: $\quad \vec{e}_{s}: \vec{e}_{s}=\vec{e}_{s 1}+\vec{e}_{m 2}$.

It is obvious that it is not possible to control independently the main and secondary subsystems of each 5-phase machines with only one 5-leg VSI, which has only four degrees of freedom ( with a wye connection). However it is possible to control only the main subsystems of the two machines. These two subsystems are respectively MM1 for the first machine and MM2 for the second machine. In this case the flux/torque of MM1 can be controlled by the 2-phase main subsystem of the inverter voltage, while the flux/torque of MM2 can be controlled by the 2-phase secondary subsystem of the inverter voltage.

Indeed, if the machines do not have sinusoidal EMF, secondary subsystem EMF harmonics (SM1 and SM2) interact with main subsystem currents (MM2 and MM1) [13]. These phenomena lead to torque ripple production whose frequencies depend on the speed of the two machines. For example, if the back EMF of machine 1 contains a third harmonic, the third back EMF harmonic of subsystem SM1 interacts with the first current harmonic of subsystem MM2 which implies a perturbation in the torque of machine 1.

One of the ways to solve this problem is to use machines with sinusoidal back EMF. In this case, the EMF related to the secondary subsystems of each machines is nullified. However this solution leads to strong constraints on machine design.

Another way in order to improve the control is to compensate the pulsating torque produced by each of the secondary subsystem SM. This last way is used and described in this work.

\section{Current control of Five Phase Permanent magnet Motor}

\subsection{Reference currents generation and control scheme.}

The inverter phase current references are created summing individual machine phase current references according to fig.1. Then we can write $[9,13]$ : 


$$
\left\{\begin{array}{l}
i_{\text {Aref }}=i_{a 1 \text { ref }}+i_{a 2 \text { ref }}=i_{a 1}=i_{a 2} \\
i_{\text {Bref }}=i_{b 1 \text { ref }}+i_{c 2 \text { ref }}=i_{b 1}=i_{c 2} \\
i_{\text {Cref }}=i_{c 1 \text { ref }}+i_{e 2 \text { ref }}=i_{c 1}=i_{e 2} \\
i_{\text {Dref }}=i_{d 1 r e f}+i_{b 2 r e f}=i_{d 1}=i_{b 2} \\
i_{\text {Eref }}=i_{\text {e1ref }}+i_{d 2 \text { ref }}=i_{e 1}=i_{d 2}
\end{array}\right.
$$

Each of the five phases of any of two machines carries simultaneously the currents of both machines.

The presented control scheme is based on an independent control of the torque of each machine. This torque loop can be associated, in real world application for each of the machines, with an outer loop speed control which can be based, for example, on the use of a classical PI controller.

We have used a classical method of torque control based on the use of PID regulators for each of the current loops. The control loop of each of the 2-phase main subsystem currents is achieved in the two dq rotating frames presented in part 2.1 and in $[17,20]$. The currents references which lead to a constant torque for the two main subsystems are constant in the two rotating d-q frames in steady state. So this method leads to a very simple and efficient control scheme in normal operations. The transfer function of open loop of the main subsystem MM1, for example, along the axis q, is given by:

$$
G_{m 1-B O}(s)=\frac{1 / R_{m 1}}{1+\frac{\Lambda_{m 1}}{R_{m 1}} . s}
$$

$\tau_{m 1}=\frac{\Lambda_{m 1}}{R_{m 1}}$ is the electrical time constant of main subsystem MM1. The currents which can be noisy are measured and filtered by a first order low pass filter included in the measurement process:

$$
G_{F T}(s)=\frac{1}{1+\tau_{f m 1} s}
$$

Hence, the transfer function of the open-loop system becomes:

$$
D_{m 1 B O}(s)=G_{F T} G_{m 1-B O}=\frac{1 / R_{m 1}}{\left(1+\tau_{f m 1} s\right)\left(1+\tau_{m 1} s\right)}
$$

We determine simplified transfer functions of closed loop:

$$
\mathrm{G}_{\mathrm{BF}}=\frac{\frac{\mathrm{kN}}{R_{s} T_{i} T_{d}}}{p^{2}+\frac{N}{T_{d}} p+\frac{k N}{R_{s} T_{i} T_{d}}}
$$

With: 
$H_{P I D}(p)=K\left[1+\frac{1}{T_{i} p}+\frac{T_{d} p}{1+\frac{T_{d}}{N} p}\right]$

Then the regulator parameters are calculated for each fictitious machine characteristics (subsystems). In our case, we have chosen to identify the closed loop system of each component of the current in the two d-q frames as a second order system (pole compensation). The cut off frequency is fixed at $\mathrm{f}_{\mathrm{c}}=\omega_{\mathrm{c}} / 2 \pi=1 \mathrm{kHz}$ and the damping coefficient $\xi \mathrm{c}$ is fixed at 0.7 . Fig3 presents a block diagram of the closed loop control scheme for the main subsystem MM1 q-axis current. For the d-axis component of these subsystems the control scheme is similar and the d-axis main subsystems currents reference is fixed to zero.

\subsection{Pulsating torque compensation}

The pulsating EM torque in the first machine is related to the q-axis current in the secondary subsystem of the first machine (SM1). This current is also a component of the $2^{\text {nd }}$ machine main subsystem current (MM2). So it is possible to use a strategy which minimizes EM pulsating torque. This minimization can be done by subtracting this component to the calculated reference current corresponding to the required torque for machine:

$I_{q m 1-t}=I_{q m 1-r e f}-I_{q s 1}$

$T_{\text {lref-t }}=T_{\text {lref }}-T_{s l}$

The second subsystem q axis current of machine 1 used for this compensation, $I_{q s I}\left(T_{s I}\right)$ is deduced from measurement of real currents in the control scheme. This strategy leads to a smooth torque control. A similar strategy is applied for the control of machine 2 current and torque $\left(I_{q-m 2}\right.$ control).

\section{Simulations and experimental results}

In order to demonstrate the performance of the presented control strategy, simulations obtained using Matlab/ Smulink and experimental results are presented and analyzed.

Firstly, figures 4 and 5 present results of simulation when the two machines have a sinusoidal EMF at different speeds. The torque of each machine remains constant and without ripples as shown in fig. 4. The 
line currents are complex since they result from a combination of currents at different frequencies in each d-q reference frame of each one of the two MM subsystems.

To prove that the two real machines can be independently controlled, the reference torque of the machine 2 is decreased as shown in fig. 5 . The speed evolution of the second machine does not have any impact on the torque quality of the first machine whose speed is thus not modified at all.

In a second case, we consider the same vector control but with trapezoidal EMF for each machine. In order to take into account this new data, spectrum of EMF given in table 1 is analysed in accordance with formula (9). In this formula it appears that the two first harmonic EMF of the main subsystem (MM) are the first and ninth harmonics, the two first harmonics of the secondary subsystem (SM) are the third and seventh. Looking at table 1, it appears that it can be considered that only the first and the third harmonics have significant values. As consequence the MM and SM subsystems can be simply modelled as two machines with sinusoidal EMF: the modelling is exactly the same as for a common three-phase machine in $\mathrm{d}$-q frame. The difference is only in the value of the rotation angle associated with the two d-q frames (generalized park transform). For SM this angle is equal to $3 p \theta$ instead of $p \theta$ for MM where $\theta$ is the angular position of the rotor of the considered machine ( 1 or 2$)$.

Fig.6 illustrates the current of the inverter and the torque when only the machine 1 is controlled (in this particular case, machine 2 reference torque is null and consequently machine 2 speed is equal to zero). The torque of the machine 1 in this case is constant without ripples. The reason is that for a 5-phase machine with EMF containing mainly the first and the third harmonics, classical vector control in MM and SM allows to obtain a constant torque without pulsation.

Fig.7 presents the simulation results obtained in the same conditions as in fig. 4 for the case of machines with trapezoidal EMF. In this case torque ripples appear in the two machines. The interaction of the current $\vec{i}_{m 2}$ (MM2) and $\vec{e}_{s 1}$ (SM1) implies a perturbation in the torque of the machine 1, and the interaction of the current $\vec{i}_{m 1}$ (MM1) and $\vec{e}_{s 2}$ (SM2) implies a perturbation in the torque of the machine 2 as shown in fig.7-(b). The frequencies of these torque pulsations are a combination of the two speeds of the two machines.

In order to compensate the torque ripples in the machine 1 , it is necessary to determine the torque related to subsystem SM1 and to use it to modify the torque reference of the subsystem MM1. In a similar 
way, to compensate the torque ripples in the machine 2 , it is necessary to determine the torque in subsystem SM2 and to use it to modify the torque reference of the subsystem MM2. Fig.8 confirms the efficiency of this compensation strategy of the torque ripples. The torque remains constant with the use of these new torque references including the compensation.

The presented approach has been implemented in a low power experimental set up. This installation is composed of two 5-phase 6-pole PMSM with trapezoidal EMF (the two machines characteristics are similar and given in appendix and the EMF waveform of these two machines is presented in fig. 2 and table 1). These two machines are associated with a 5-leg DSP-controlled VSI drive. The switching frequency of the VSI is fixed at $12 \mathrm{kHz}$ in all the studied cases. Fig. 13 presents a snapshot of this experimental set-up. The overall system is controlled by a DS1005 controller board for DSpace. The sampling time has been set to $100 \mu \mathrm{s}$.

To confirm the validation of the proposed control, the experimental results are presented in the same conditions as in the simulated cases. Fig.9 shows the current of the inverter and the torque when only the machine 1 is controlled (the reference torque of the machine 2 is nullified and the associated speed equal to zero). In this case the torque of machine 1 is constant. When both machines are controlled simultaneously, torque ripples appear in each machine as shown in fig.10. In a second case reference torque is modified to compensate the ripples as described previously. This strategy leads to obtain smooth torques for the two machines as illustrated in fig 11. The table 2 shows the values of the torque oscillation (with and without torque compensation) in the case of fig 10 and fig 11 where the two machines are controlled with two different reference torques.

To demonstrate the independent control of two machines as show in simulation (case of fig. 5), the torque reference of machine 2 is decreased as shown in fig 12 . We observe that the current of the inverter is modified, and that the speed and the torque of machine 2 are modified. The modification of the torque reference of machine 2 has not any impact on the torque or the speed of the machine 1 . The torque ripples are efficiently compensated.

\section{Conclusion}

This paper focuses on the robustness and efficiency of the multi-machine control of two 5-phase 
PMSM with trapezoidal EMF connected in series and supplied by a single 5-phase inverter. A mathematical modelling of the drive system based on a generalized Concordia transform is presented. This theory allows the determination of an independent control scheme for the two machines. Simulations and experimental results show that the independent control of two series -connected machines is possible.

In order hand, the influence of EMF harmonics of the two machines in this configuration is discussed and illustrated by simulation and experimental results. It is shown that EMF harmonics can interact with the winding currents and leads to a prohibitive level of torque ripple. This phenomenon is particularly penalizing in the case of machines with trapezoidal EMF. A compensation strategy is proposed. This strategy is based on a new calculation the reference torques of the two machines taking into account these parasitic effects. Experimental and simulation results demonstrate the efficiency of the proposed strategy to control independently two 5-phase PMSM with trapezoidal EMF in order to reach high level requirements in terms of torque quality.

\section{Appendix}

\section{-Generalized Concordia transform}

The generalized Concordia transformation is characterized by the $\left[\mathrm{C}_{5}\right]$ matrix $[10,14,25]$. This matrix for a five phase system, is:

$C_{5}=\sqrt{\frac{2}{5}}\left[\begin{array}{ccccc}\frac{1}{\sqrt{2}} & 1 & 0 & 1 & 0 \\ \frac{1}{\sqrt{2}} & \cos \frac{2 \pi}{5} & \sin \frac{2 \pi}{5} & \cos \frac{4 \pi}{5} & \sin \frac{4 \pi}{5} \\ \frac{1}{\sqrt{2}} & \cos \frac{4 \pi}{5} & \sin \frac{4 \pi}{5} & \cos \frac{8 \pi}{5} & \sin \frac{8 \pi}{5} \\ \frac{1}{\sqrt{2}} & \cos \frac{6 \pi}{5} & \sin \frac{6 \pi}{5} & \cos \frac{12 \pi}{5} & \sin \frac{12 \pi}{5} \\ \frac{1}{\sqrt{2}} & \cos \frac{8 \pi}{5} & \sin \frac{8 \pi}{5} & \cos \frac{16 \pi}{5} & \sin \frac{16 \pi}{5}\end{array}\right]$

- conjugate notation:

$\vec{A}^{*}=\vec{A}_{x} \vec{x}-\vec{A}_{y} \vec{x}$ for $\vec{A}=\vec{A}_{x} \vec{x}+\vec{A}_{y} \vec{x}$

This notation is used in equations (8) and (9) to traduce in vectorial notation the effect of the special connection of the two machines 
- Data of experimental machine:

Rs $=0.65 \Omega ; \mathrm{L}=1.10 \mathrm{mH}, \mathrm{M}_{1}=0.03 \mathrm{mH}, \mathrm{M}_{2}=0.21 \mathrm{mH}, \Lambda_{\mathrm{m}}=1.5 \mathrm{mH}, \Lambda_{\mathrm{s}}=0.97 \mathrm{mH}$.

$\mathrm{P}=300 \mathrm{~W}$ (rated power); $\mathrm{N}=3500 \mathrm{tr} / \mathrm{min}$ (rated speed); $\mathrm{U}_{\mathrm{dc}}=60 \mathrm{~V}$ (DC bus Voltage)

\section{References}

[1] C. Gerada, K. Bradley, H. Xiaoyan, A. Goodman, C. Whitley,G. Towers, , "A 5-Phase FaultTolerant Brushless Permanent Magnet Motor Drive for an Aircraft Thin Wing Surface Actuator," Electric Machines \& Drives Conference, 2007. IEMDC '07. IEEE International , vol.2, no., pp.16431648, 3-5 May 2007

[2] G.J. Atkinson, B.C. Mecrow, A.G. Jack, D.J. Atkinson, P. Sangha, M. Benarous, "The Analysis of Losses in High-Power Fault-Tolerant Machines for Aerospace Applications," Industry Applications, IEEE Transactions on , vol.42, no.5, pp. 1162-1170, Sept.-Oct. 2006,

[3] A.S.Thomas, Z.Q. Zhu, Z.Q.; R.L. Owen, G.W.Jewell, D. Howe, "Multiphase Flux-Switching Permanent-Magnet Brushless Machine for Aerospace Application," Industry Applications, IEEE Transactions on , vol.45, no.6, pp.1971-1981, Nov.-dec. 2009

[4]L. Lillo, L. Empringham, P.W. Wheeler, S. Khwan-On, C. Gerada, M.N. Othman, H. Xiaoyan , "Multiphase Power Converter Drive for Fault-Tolerant Machine Development in Aerospace Applications," Industrial Electronics, IEEE Transactions on , vol.57, no.2, pp.575-583, Feb. 2010

[5] S. Williamson, S. Smith, "Fault tolerance in multiphase propulsion motors", Journal of Marine Engineering and Technology, no. A4 2004

[6] J. Apsley, S. Williamson, "Analysis of multiphase induction machines with winding faults," Industry Applications, IEEE Transactions on , vol.42, no.2, pp. 465-472, March-April 2006

[7] F. Scuiller, E. Semail, J.-F. Charpentier, P. Letellier, "Multi-criteria-basisd design approach of multi-phase permanent magnet low-speed synchronous machines, IET Electr. Power Appl., 2009, Vol. 3, Iss. 2, pp. 102-110

[8] "IEEE Guide for the Design and Application of Power Electronics in Electrical Power Systems on Ships," IEEE Std 1662-2008, pp.C1-60, March 192009 
[9] A. Iqbal, S.N. Vukosavic, E. Levi, M. Jones, H.A. Toliyat ''Dynamics of a Series-Connected Two-Motor Five-Phase Drive System with a Single-Inverter supply.' in Proceedings of the IEEE-IAS annual meetings, Oct. 2005, Vol2, pp.1081 - 1088

[10] E. Levi, M. Jones, S.N. Vukosavic, H.A. Toliyat, "A Novel Concept of a Multiphase, Multimotor Vector Controlled Drive System Supplied From a Single Voltage Source Inverter", IEEE Transactions on Power Electronics, vol. 19, no. 2, March 2004, pp. 320-335.

[11] E. Levi, M. Jones, S.N.Vukosavic, H..A .Toliyat" Operating Principles of a Novel Multiphase Multimotor Vector -controlled Drive. IEEE Transactions on Energy Conversion, Vol.19.NO.3, September 2004 pp 508-517.

[12] E. Levi, M. Jones, S.N. Vukosavic " A Series-Connected Two-Motor Six-Phase Drive With Induction and Permanent Magnet Machines." IEEE Transactions on Energy Conversion, Vol.21.NO.1, March 2006 pp 121-129.

[13] E. Levi, M. ones, S.N. Vukosavic, A. Iqbal, H.A. Toliyat, "Modeling, Control, and Experimental Investigation of a Five-Phase Series-Connected Two-Motor Drive With Single Inverter Supply," Industrial Electronics, IEEE Transactions on , vol.54, no.3, pp.1504-1516, June 2007

[14] E. Semail, E. Levi, A Bouscayrol, X. Kestelyn " Multi-Machine Modelling of Two Series Connected 5-phase Synchronous Machines: Effect of Harmonics on Control. ' EPE 2005

[15] S. Gataric, "A polyphase cartesian vector approach to control of polyphase AC machines," IEEE Industry Applications Conference, vol.3, no., pp.1648-1654 vol.3, 2000

[16] L. Parsa, H. A. Toliyat "Multi-phase Permanent Magnet Motor Drives" in Proceedings of the IEEE-IAS annual meetings 2003, Salt Lake City (Utah), October 12-16,

[17] L. Parsa, H. A.Toliyat 'Five- Phase Permanent -Magnet Motor Drives'” IEEE Transactions on Industry applications, Vol.41.NO.1, January/ February 2005 pp 30-37.

[18] E. Semail , X. Kestelyn , F. Locment, "Fault Tolerant Multiphase Electrical Drives: The Impact of Design”, EPJ AP (European Physical Journal-Applied Physics), Vol 43, n², August 2008 pp. 159163 
[19] S. Dwari,L. Parsa,, "Fault-Tolerant Control of Five-Phase Permanent-Magnet Motors With Trapezoidal Back EMF," Industrial Electronics, IEEE Transactions on, vol.58, no.2, pp.476-485, Feb. 2011

[20] F.Mekri, J.F. Charpentier, S. Benelghali, X.Kestelyn’' Simulation and Experimental Validation of Control of Five Phase Permanent magnet Motor under Open Circuit Fault Conditions"' IEEE VPPC 2010, Lille, France.

[21] F. Locment, E.Semail, Kestelyn " Vectorial Approach Based Control of a seven- phase Axial Flux Machine Designed for Fault Operation, IEEE Trans on Ind. Electronics, Vol 55 Issue 10, Oct 2008-pp $3682-3691$

[22] JP Martin, S. Pierfederici, F. Meibody -abar, P. Letellier, «Synthèse des méthodes de filtrage du couple des MSAP Polyphasées en modes normal et dégrade »', European Journal of Electrical Engineering- 2007, Volume 10, ${ }^{\circ} 1-2$ pp 117-149.

[23] S. Dwari, L. Parsa '’An Optimal Control Technique for Multiphase PM Machines Under Open Circuit Fautls',,IEEE Transactions on Industry Electonics, Vol.55.NO.5, May 2008, pp 1988 - 1995.

[24] L. Parsa, H.A. Toliyat, "Fault-Tolerant Interior-Permanent-Magnet Machines for Hybrid Electric Vehicle Applications," Vehicular Technology, IEEE Transactions on , vol.56, no.4, pp.1546-1552, July 2007.

[25] L. Parsa, H A.Toliyat ,' Sensorless Direct Torque Control of Five Phase Interior Permanent Magnet Motor Drives', IEEE Transactions on Industry applications, Vol.43.NO.4, July/August 2007 pp $952-959$.

\section{List of Tables}

1. Harmonic contents of the back EMF the experimental 5-phase PMSM

2. Torque oscillations in the case of trapezoidal EMF without/with compensation of torque ripples and the two machines at different constant speeds.

\section{List of Figures}


1. Particular series connection for independent control of two 5-phase machines.

2. EMF of the experimental 5 phase PM-machine

3. Block diagram of the current control for each main subsystem q-axis current (Iq-m1 or Iq-m2)

4. Simulation results with sinusoidal EMF: (a) Current in five phases of inverter, (b) torques (T1: machine1 and T2: machine).

5. Simulation result with sinusoidal EMF: (a) Current in the five phases of inverter, (b) torques and (c) speed of the two machines.

6. Simulation results with trapezoidal EMF and one machine control: (a) Current in five phases of inverter, (b) torque.

7. Simulation result with trapezoidal EMF without compensation of torque ripples: (a) Current in five phases of inverter, (b) torque.

8. Simulation result with trapezoidal EMF with compensation of torque ripples: (a) Current in five phases of inverter, (b) torque.

9. Experimental result with trapezoidal EMF: (a) Current in five phases of inverter, (b) torque

10. Experimental result with trapezoidal EMF without compensation of torque ripples: (a) Current in five phases of inverter, (b) torque.

11. Experimental results with trapezoidal EMF with compensation of torque ripples: (a) Current in five phases of inverter, (b) torque

12. Experimental result with trapezoidal EMF: (a) Current in the five phases of inverter, (b) torques and

(c) speed of the two machines

13. Snapshot of the experimental test-bed

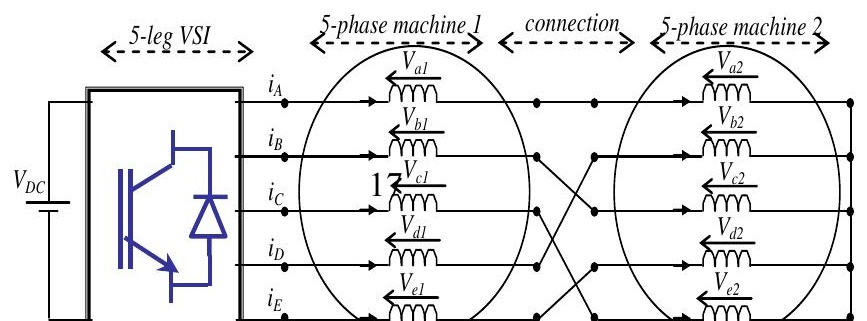


Fig. 1. Particular series connection for independent control of two 5-phase machines.

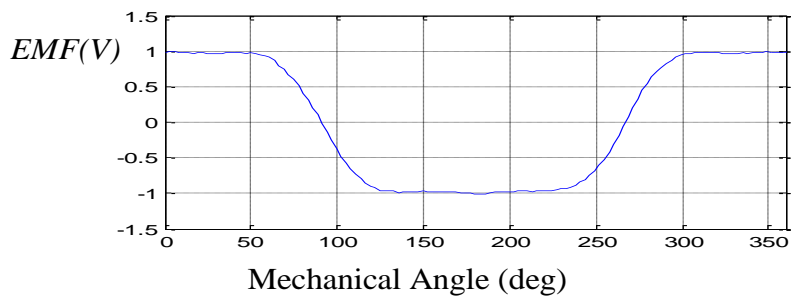

Fig. 2. EMF of the experimental 5 phase PM-machine

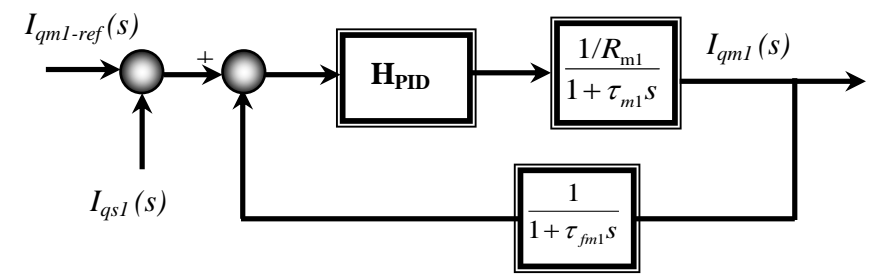

Fig. 3. Block diagram of the current control for each main subsystem q-axis current ( $I_{q-m l}$ or $I_{q-m 2)}$ 


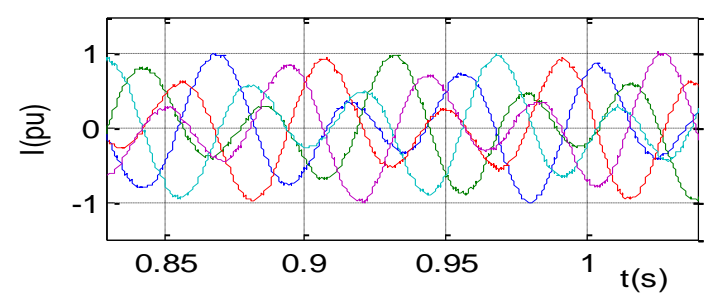

(a)

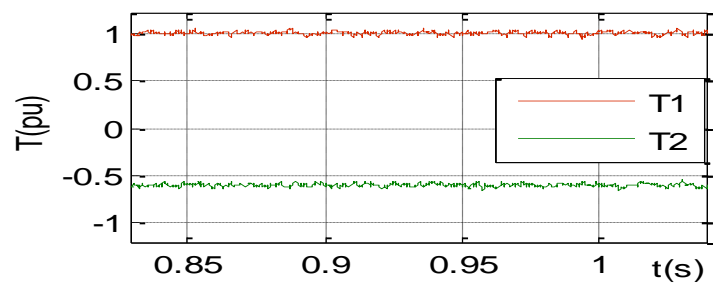

(b)

Fig. 4. Simulation results with sinusoidal EMF: (a) Current in five phases of inverter, (b) torques (TI: machine1 and $T 2$ : machine 2).

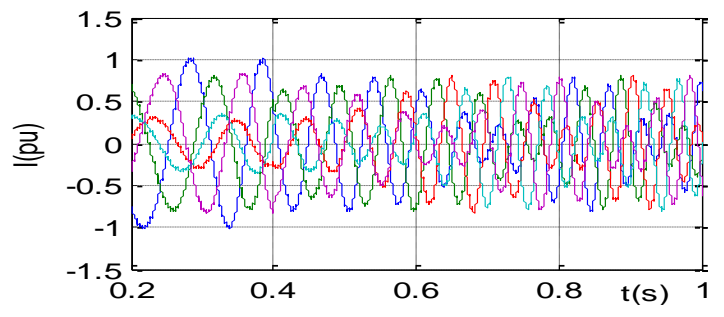

(a)

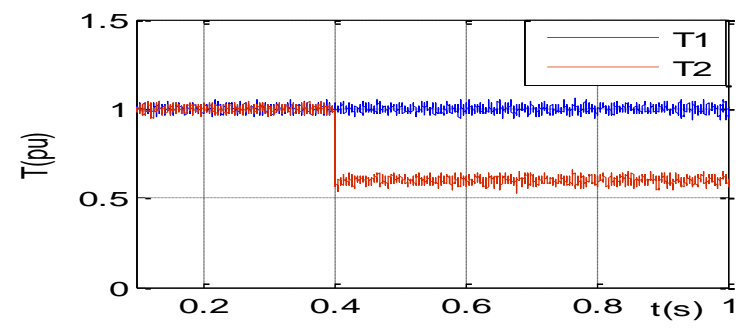

(b)

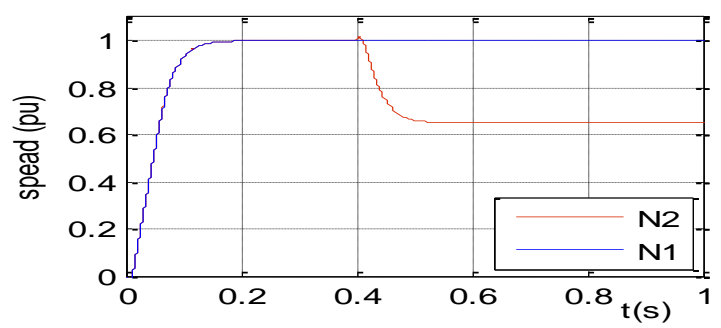

(c)

Fig.5. Simulation result with sinusoidal EMF: (a) Current in the five phases of inverter, (b) torques and (c) speed of the two machines. 


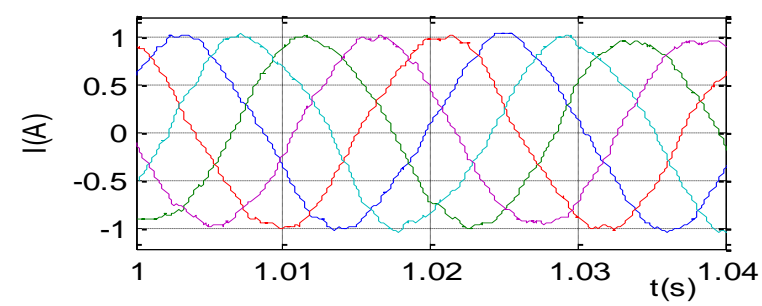

(a)

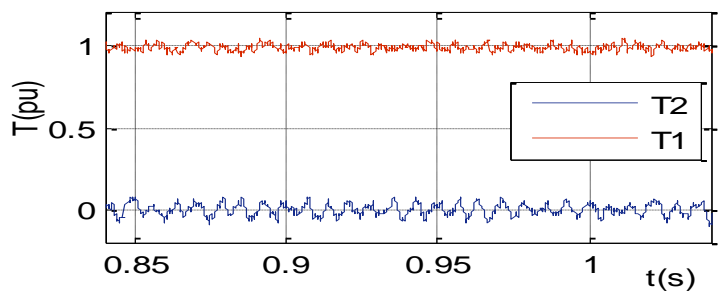

(b)

Fig.6. Simulation results with trapezoidal EMF and and T2 machine at zero speed: (a) Current in five phases of inverter, (b) torque.

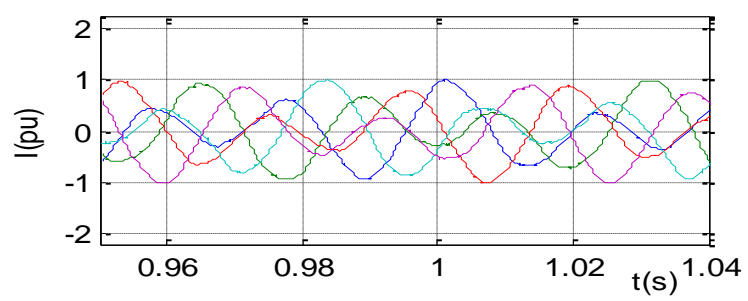

(a)

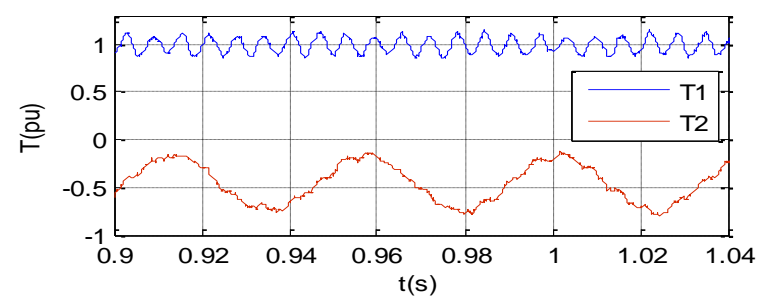

(b)

Fig.7. Simulation result with trapezoidal EMF without compensation of torque ripples and the two machines at different constant speeds: (a) Current in five phases of inverter, (b) torque.

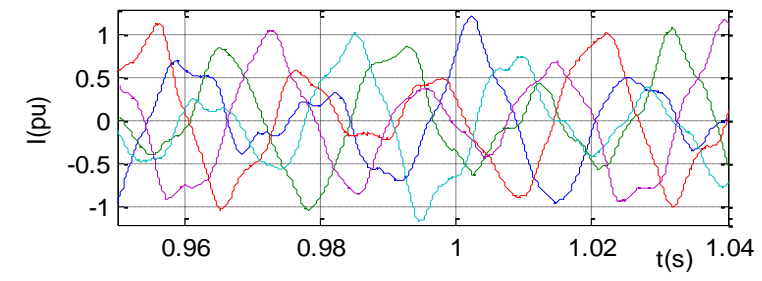

(a) 


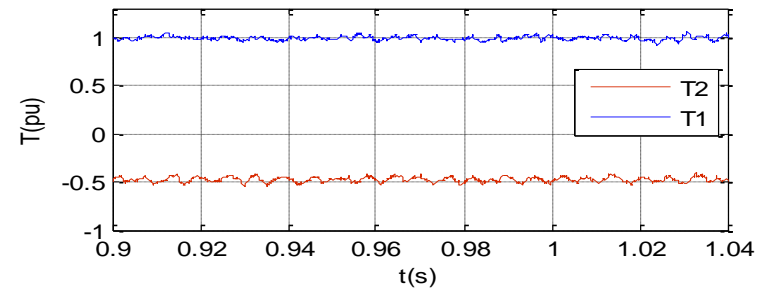

(b)

Fig. 8. Simulation result with trapezoidal EMF with compensation of torque ripples and the two machines at different constant speeds: (a) Current in five phases of inverter, (b) torque.

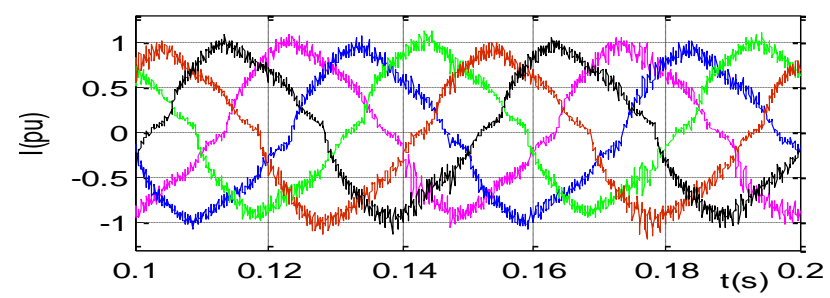

(a)

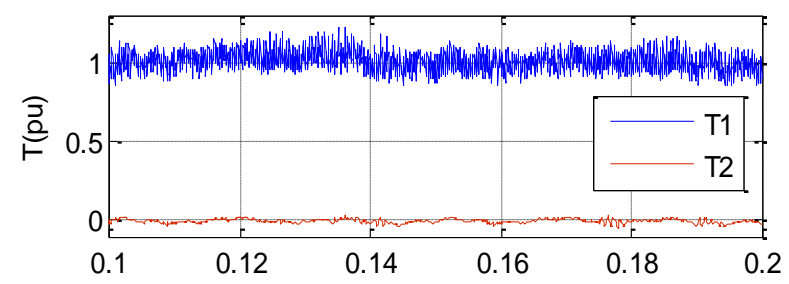

(b)

Fig. 9. Experimental result with trapezoidal EMF and T2 machine at zero speed: (a) Current in five phases of inverter, (b) torque

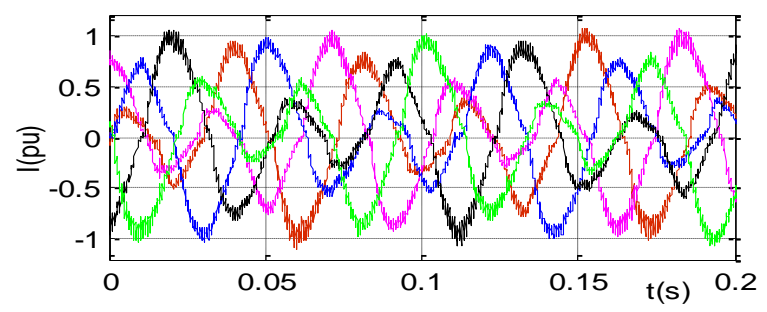

(a)

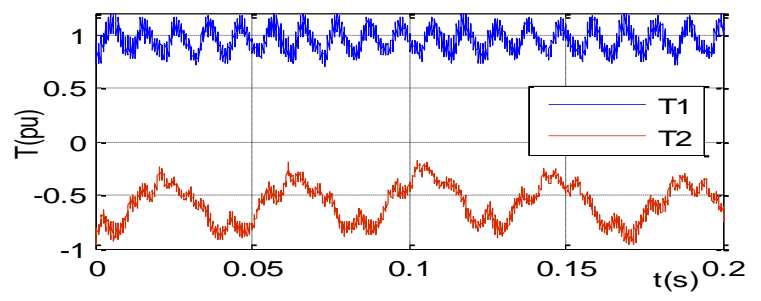

(b)

Fig. 10. Experimental result with trapezoidal EMF without compensation of torque ripples and the two machines at different constant speeds: (a) Current in five phases of inverter, (b) torque. 


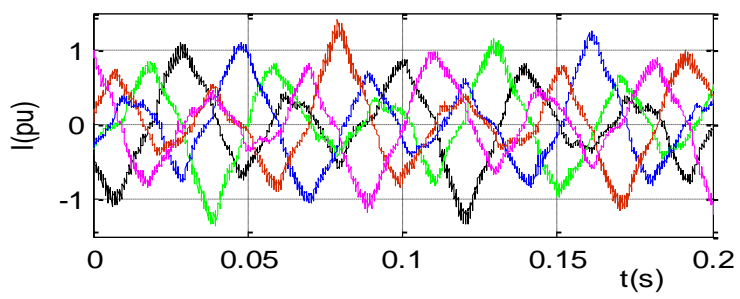

(a)

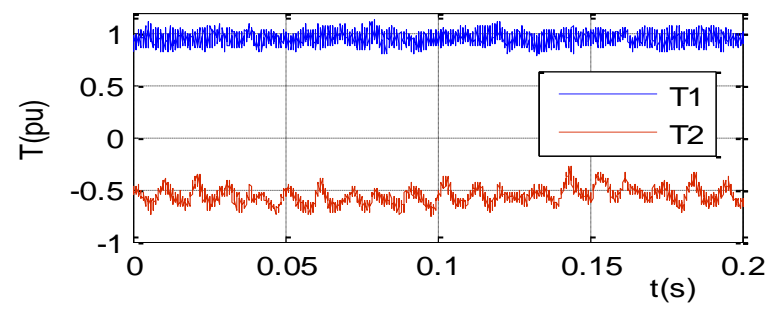

(b)

Fig.11. Experimental results with trapezoidal EMF with compensation of torque ripples and the two machines at different constant speeds: (a) Current in five phases of inverter, (b) torque.

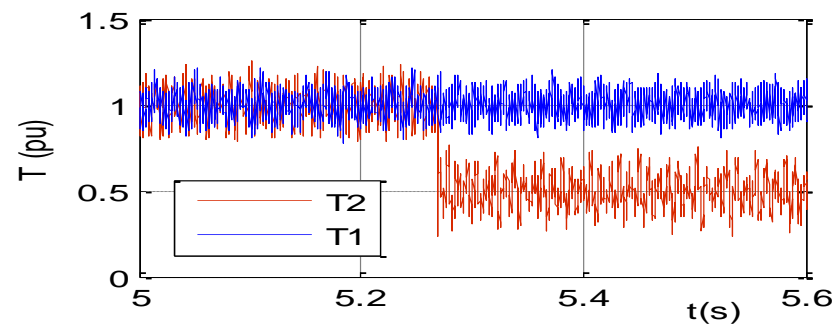

(b)

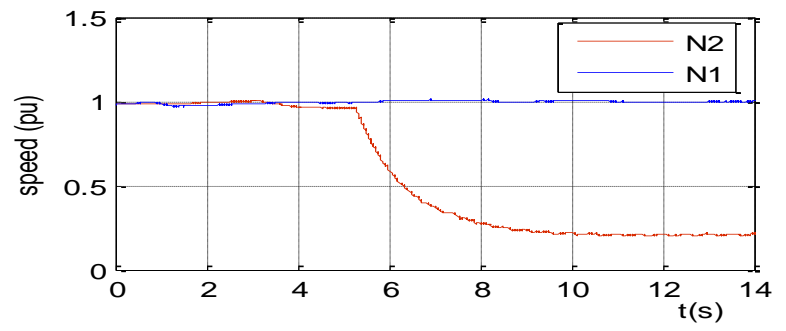

(c)

Fig.12. Experimental result with trapezoidal EMF in transient operation: (a) Current in the five phases of inverter, (b) torques and (c) speed of the two machines. 


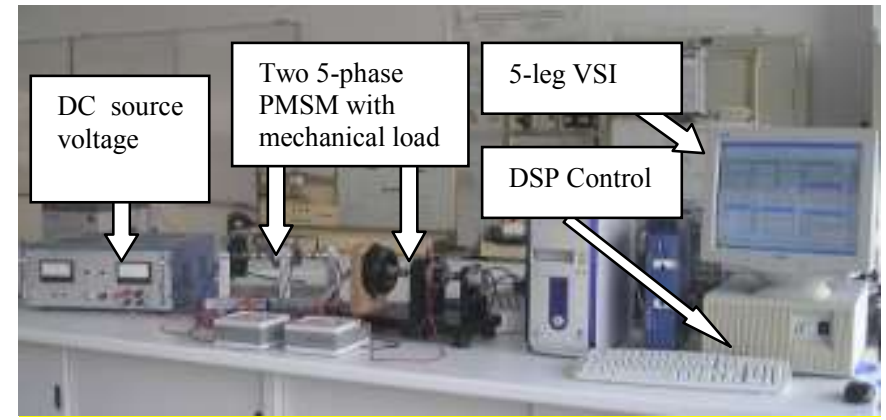

Fig. 13. Snapshot of the experimental test-bed (VSI is behind the computer)

\begin{tabular}{|l|l|l|l|l|}
\hline Harmonic number & 1 & 3 & 5 & 7 \\
\hline Relative RMS Amplitude & 100 & 23 & 7.31 & 0.82 \\
\hline
\end{tabular}

Table1: Harmonic contents of the back EMF the experimental 5-phase PMSM.

\begin{tabular}{|l|c|c|}
\hline & $\mathrm{T}_{1}$ oscillation $\%$ & $\mathrm{~T}_{2}$ oscillation $\%$ \\
\hline Without compensation & 10 & 60 \\
\hline With compensation & 3 & 8.6 \\
\hline
\end{tabular}

Table2: Torque oscillations in the case of trapezoidal EMF without /with compensation of torque ripples and the two machines at different constant speeds. 